\title{
Comparing Social Climate Perceptions of Staff and Juveniles with Sexual Behavior Problems
}

\author{
Johnson TL1, Underwood LA2*, Dailey FLL², Williams C ${ }^{2}$ and Crump Y3 \\ ${ }_{1}^{1}$ MidAmerica Nazarene University Counselor Education Program, USA \\ 2Regent University School of Psychology \& Counseling, USA \\ ${ }^{3}$ Louisiana Office of Juvenile Justice, USA
}

*Corresponding author: Lee A Underwood, Psy.D, Regent University School of Psychology \& Counseling, 1000 University Drive, CRB 215, Virginia Beach, Virginia 23464, USA, Tel: (757) 630-4442; Email: leeunde@regent.edu

\begin{abstract}
Increases in research on juvenile sexual behavior problems have created a need for more evidence-based treatment.Furthermore, literature shows that the social climate of a treatment facility is an important variable, yet more empirical data exploring how it impacts juveniles with sexual behavior problems in secure care facilities is needed.This study evaluated the perceived social climate of both staff and juveniles in two secure care facilities; as measured by a onetime administration of the Ward Atmosphere Scale (WAS).The total sample consisted of 56 subjects, of which35 were adjudicated male juveniles with sexual behavior problems $(n=35)$ and 21 were staff $(n=21)$.Overall, the staff and juveniles' social climate perceptions were found to be significantly different in the System Maintenance higher order domain of the WAS.Additionally, preliminary data analysis discovered that the two sites were statistically significantly different for the WAS subscales of Order and Organization, Support, Involvement, as well as the higher order domains of System Maintenance and Relationship.Finally, the theoretical and practical implications, strengths and limitations, recommendations for future research and practices for this study are discussed.
\end{abstract}

Keywords: Juveniles with Sexual Behavior Problems; Secure Care; Social Climate; Ward Atmosphere Scale

\section{Introduction}

The amount of programs for juveniles with sexual behavior problems has grown in the past 30 years [1], and the literature suggests that juveniles with sexual behavior problems who have received treatment have reduced sexual recidivism rates as compared to juveniles who have [2-4]. While some researchers argue in favor of the positive effects of treatment, there has also been a confluence of research that emphasizes the collateral damage created from the iatrogenic effect of deviancy training created when delinquent peers are placed in confined spaces [5-8].

Awareness of juveniles with sexual behavior problems has dramatically intensified based on greater societal consciousness, increased advocacy on behalf of victims, and juveniles becoming more educated about the judicial system [9]. As of 2007, statistics regarding juveniles with sexual behavior problems show that juveniles committed 


\section{Mental Health \& Human Resilience International Journal}

22 percent of all sex crimes and 15 percent of forcible rapes [10]. In recent years, more information has been gathered to help build knowledge and awareness towards identifying and understanding these juveniles with greater focus; however, the majority of sex offender data resides within the realm of adult offenders. Juveniles have often remained a subset of the population with which researchers and clinicians have historically experienced difficulty [10-12] in formulating a clear conceptualization of the origins, characteristics, or consistent treatment that decreases recidivism of their acting out [2].

Due to this increased awareness, and subsequent need for rehabilitation treatment, different levels of programs have been established across the country. Furthermore, literature surrounding a common form of care, as well as progression of correction for juveniles with sexual behavior problems has produced contrasting interpretations of their efficacy in reducing recidivism [13]. Pratt (2013) [12] argued for a placement system that takes into consideration the juvenile's risk assessment of their detrimental impact on the community. Several studies have discovered that juveniles who have entered into residential treatment facilities show a reduction in negative symptoms (e.g., aggression, depression, anxiety, suicidality), a rise in daily functioning, and high rates of school completion within the course of treatment as well as post-treatment $[14,15]$. Conversely, the newfound structure of a treatment program, in relation to the juvenile's previous experience with chaos, abuse and neglect in their families of origin or ecological context of school, neighborhood, and community [16], may create confusion and discomfort for them. Rates of juveniles with sexual behavior problems who have experienced sexual abuse range from 40 to $80 \%$, and the prevalence of physical abuse within this population ranges from 25 to $50 \%$ [17].

While some research produces data that maintains support for the efficacy of home or community based treatment programs for juvenile offenders of all types $[18,19]$, other research in the field calls attention to the shifting trend of relying more heavily on the juvenile justice system and secure care facilities to provide treatment for juveniles with sexual behavior problems in particular [20] For many with mental health disorders, this is their first line of treatment [21]. The result has been an increased need for these facilities to be able to provide effective treatment to the juveniles that have been placed with them.
Researchers are in agreement that the social environments, and climate of the juvenile while in treatment programs, possess significant implications for juvenile satisfaction, motivation, as well as treatment outcomes [22-25]. Specifically, Beech and HamiltonGiachritsis (2005) [26] conducted research that discovered a correlation between the correctional facility's social climate and treatment success of adult sexual offenders. The iatrogenic effect of deviancy training often experienced in secure care facilities, has been found to be a contributing factor in the treatment effectiveness of these programs [8]. This inverse relationship produces lower treatment efficacy the higher the iatrogenic effects within a facility. Ultimately, the research related to the social climates of programs for juveniles with sexual behavior problems in secure care remains scarce, with much of it focused on juveniles with non-sexual offenses, $[8,27,28]$ even though secure care is the most likely treatment employed for those with the highest risk for recidivism $[6,20]$.

Additionally, Jörgensen, Römma, and Rundmo (2009) [23] utilized the Ward Atmosphere Scale and discovered a correlation between the Ward Atmosphere Scale and juvenile satisfaction, while acknowledging more research was necessary. Social climate has been a concept researched in the previous decades [25,29-31], and focused on the perspective within a hospital inpatient unit as opposed to correctional centers.

\section{Purpose of the Study}

The purpose of this study is to compare the potential differences that may exist between the staff and juveniles' perception of the social climate. Previous research has discovered similarities in certain areas of social climate when comparing staff and resident scores regarding social climate, while there remain specific variables of the social climate in which their respective perceptions diverge (e.g., support, open expression of feelings, practical skills education, open defiance and anger) [32]. Therefore, data analysis will be concentrated on particular scores (detailed in the next section) from the administration of the Ward Atmosphere Scale to staff and juveniles.

\section{Methods}

The purpose of this section is to provide details germane to this study in order for potential future research to have a methodological framework from which to continually build. Initially, this was accomplished by 


\section{Mental Health \& Human Resilience International Journal}

delineating essential terms within this study to provide a common language, as well as extrapolating upon the rationale found within literature for the particular research questions and hypotheses put forth by this study. Further information will be provided on research methodology and design, population and sampling, and data collection (e.g., instrumentation, procedures, dependent and independent variables). Additionally, a step-by-step description of the statistical analysis, and how it was aligned with the specific design of the research study will be produced.

\section{Definition of Terms}

Juveniles with sexual behavior problems and the various factors surrounding this population have, historically, been greatly misunderstood which has subsequently inhibited research. This section defines the essential terms of this study in order to maintain an objective and cohesive understanding throughout.

Cognitive distortions - "Various thoughts, perceptions, beliefs and ideas that are understood to present obstacles to the offender taking responsibility for his crimes, and that taking responsibility is understood to be essential to effective treatment" [33].

Community based treatment programs -Programs where individuals are placed with their natural family, foster or mentor homes, while receiving oversight from probation officers and/or a mental health provider $[34,35]$.

Deviancy training - The process by which juveniles placed within a deviant group will experience an exacerbation and consolidation of their antisocial behaviors [36].

Iatrogenic effect -The "expressions of the amenable and adaptive human subject adhering or complying with the situational constraints and contexts laid out by the avid and enthusiastic but eventually misguided researcher" [37].

Juveniles with sexual behavior problems -Individuals whose ages range between 12 and 25 that have perpetrated a sexual offense against another person of any age [38].

Secure care facilities - Facilities that detain their youth in-house, have highly structured atmospheres, and maintain separation from the community.
Social climate - The way an individual views their environment; which can encompass contributing variables such as physical space, individuals in a shared setting, interpersonal relationships, and intrapersonal matters [32].

Staff - Employees of a secure-care facility who are responsible for the supervision, monitoring and care of juveniles with sexual behavior problems.

\section{Research Questions and Hypotheses}

The following research questions were identified for this study:

RQ1: Is there a statistically significant difference between the WAS Personal Problem Orientation subscale scores of juveniles, and the WAS Personal Problem Orientation subscale scores of the staff in secure care sites?

RQ2: Is there a statistically significant difference between the WAS Support subscale scores of juveniles, and the WAS Support subscale scores of the staff in secure care sites?

RQ3: Is there a statistically significant difference between the WAS Involvement, and Anger and Aggression subscale scores of juveniles, and the WAS Involvement, and Anger and Aggression subscale scores of the staff in secure care sites?

RQ4: Is there a statistically significant difference between the WAS System Maintenance domain scores of juveniles, and the WAS System Maintenance domain scores of the staff in secure care sites?

RQ5: Is there a statistically significant difference between the WAS Relationship domain scores of juveniles, and the WAS Relationship domain scores of the staff in secure care sites?

The following hypotheses were developed for this study:

H1: There will be a statistically significant difference between the WAS Personal Problem Orientation subscale scores of juveniles, and the WAS Personal Problem Orientation subscale scores of the staff in secure care sites.

H2: There will be a statistically significant difference between the WAS Support subscale scores of juveniles, and the WAS Support subscale scores of the staff in secure care sites.

H3: There will be a statistically significant difference between the WAS Involvement, and Anger and Aggression subscale scores of juveniles, and the WAS Involvement, and Anger and Aggression subscale scores of the staff in secure care sites. 


\section{Mental Health \& Human Resilience International Journal}

H4: There will be a statistically significant difference between the WAS System Maintenance domain scores of juveniles, and the WAS System Maintenance domain scores of the staff in secure care sites.

H5: There will be a statistically significant difference between the WAS Relationship domain scores of juveniles, and the WAS Relationship domain scores of the staff in secure care sites.

\section{Research Design}

"An [important] element of quantitative research relates to a more planned sourcing process in which the researcher has a definitive or clean objective as a basis from which to research" [39]. Therefore, this study used an ex post facto quantitative research methodology to examine the pre-determined, identified questions regarding the differences between social climate of staff and juveniles with sexual behavior problems in secure care settings. Data from the subjects was collected at one time, with the instrument previously completed by juveniles and staff, and the results were collated into a database and analyzed by SPSS.

Specifically, this investigation will use a correlational study as its primary design because the foundational questions addressed by the study are that of group differences, and quantitative studies are best suited for examining and analyzing complex differences in quantifiable ways [40]. Lutz and Hill (2009) [41] reiterated this as they noted, "Quantitative research methods are helpful tools for achieving these goals because they help us study the complex relationship between the patient [youth], the therapist, the process of therapy, external events in the life of [youth], and insession progress, post session progress, and therapy outcome at the end of treatment as well as during the follow-up period; they can also help us aggregate and integrate findings about psychotherapy".

This study asks what difference, if any, exists between social climate perceptions of staff and juveniles in secure care treatment facilities. The research design was selected because the variable was not manipulated for the purposes of research [42]. "Participants in these types of studies are assumed to possess the characteristics of interest prior to the study, and they are measured on those characteristics during the study, no attempt is made by the researchers to change them" [42]. As such, the researchers will utilize the independent t-test design to quantitatively analyze the difference between these variables so as to better establish and understand their distinction, or connection, with one another. To the knowledge of this author, there has been no other empirical study examining staff and resident perceptions of social climate in secure care facilities for juveniles with sexual behavior problems, which makes this design an appropriate methodology of choice.

\section{Population and Sampling}

The current study was designed to explore the differences between perceptions of social climate for staff and juveniles with sexual behavior problems in secure care treatment facilities. In 2008, the Office of Juvenile Justice (OJJ) developed a continuum of services, which involved a three-tiered model treatment: secure care facilities, community based residential nonsecure facilities, and community based outpatient clinics [38]. In the secure care facility, juveniles are placed in either the general population, or more structured dormitories depending on their assessed risk for recidivism [38]. The two secure care facilities that housed the research participants are included in this study.

Participants in this study consisted of male juveniles who were adjudicated by a court magistrate to either a secure care program or a non-secure program after committing sexually aggressive crimes. All juveniles completed the Sexual Behavior Problem Treatment Program (SBPTP), were 12-21 years of age (as defined by state legal statutes), and were adjudicated sometime in between the years of 2008 and 2014. The respondents for the WAS consisted of 56 total respondents, which included juveniles $(n=35)$ as well as staff $(n=21)$. Archived demographic information for respondents of the WAS was incomplete; it did not specify ethnicity for either juveniles or staff, and age was only recorded for 3 SCY staff members $(53,56,59$, respectively). Additionally, the gender for 8 of the 21 staff members was identified as female.

\section{Instrumentation}

Ward Atmosphere Scale (WAS): The Ward Atmosphere Scale (WAS) (Table 1) (Moos, 1996) [43] is a self-report measure consisting of 100 brief statements on the WAS (10 per scale), answering true or false whether the statement was indicative of their ward. Ten subscales tap three higher order domains: (1) Relationships, (2) Personal Growth, and (3) System Maintenance. The Relationship domain includes the subscales: Involvement, Support, and Spontaneity. The Personal Growth domain includes: Autonomy, Practical Orientation, Personal Problem Orientation, and Anger and Aggression. The 


\section{Mental Health \& Human Resilience International Journal}

three System Maintenance scales are: Order and Organization, Program Clarity, and Staff Control [32].

The 10 subscales have displayed respectable internal consistency (.68 to .83), high item-to-subscale correlations, and high test-retest reliability for all subscale [44]. Moreover, previous research has confirmed both the content [45] and criterion validity [46] of the WAS. Additionally, it has been implemented in several cross-cultural contexts [24,29,31,47].

\begin{tabular}{|c|c|}
\hline $\begin{array}{c}\text { Category } \\
\text { Relationship }\end{array}$ & Description \\
\hline 1. Involvement & $\begin{array}{l}\text { How active and energetic patients } \\
\text { are in the ward }\end{array}$ \\
\hline 2. Support & $\begin{array}{c}\text { The extent to which patients help } \\
\text { and support each other and how } \\
\text { supportive the staff are towards } \\
\text { patients }\end{array}$ \\
\hline $\begin{array}{l}\text { 3. Spontaneity } \\
\text { Personal Growth }\end{array}$ & $\begin{array}{l}\text { The extent to which the program } \\
\text { encourages the open expression of } \\
\text { feelings by patients and staff }\end{array}$ \\
\hline 4. Autonomy & $\begin{array}{l}\text { How self-sufficient and independent } \\
\text { are the patients in making their own } \\
\text { decisions }\end{array}$ \\
\hline $\begin{array}{l}\text { 5. Practical } \\
\text { Orientation }\end{array}$ & $\begin{array}{l}\text { The extent to which patients learn } \\
\text { practical skills and are prepared for } \\
\text { discharge from the ward }\end{array}$ \\
\hline $\begin{array}{l}\text { 6. Personal } \\
\text { Problems } \\
\text { Orientations }\end{array}$ & $\begin{array}{l}\text { The extent to which patients seek to } \\
\text { understand their feelings and } \\
\text { personal problems }\end{array}$ \\
\hline $\begin{array}{l}\text { 7. Anger and } \\
\text { Aggression } \\
\text { System } \\
\text { Maintenance }\end{array}$ & $\begin{array}{l}\text { The extent to which patients argue } \\
\text { with other patients and staff, } \\
\text { become openly angry and display } \\
\text { other aggressive behavior }\end{array}$ \\
\hline $\begin{array}{l}\text { 8. Order and } \\
\text { Organization }\end{array}$ & $\begin{array}{c}\text { How important are order and } \\
\text { organization in the ward }\end{array}$ \\
\hline $\begin{array}{l}\text { 9. Program } \\
\text { Clarity }\end{array}$ & $\begin{array}{l}\text { The extent to which patients know } \\
\text { what to expect in their day-to-day } \\
\text { routine, and the explicitness of ward } \\
\text { rules and procedures }\end{array}$ \\
\hline 10. Staff Control & $\begin{array}{l}\text { The extent to which the staff use } \\
\text { measures to keep patients under } \\
\text { necessary control }\end{array}$ \\
\hline
\end{tabular}

Table 1: Ward Atmosphere Scale (WAS) three higher order domains and ten subscales [23].

\section{Subjects}

Subjects who had entered into the Sexual Behavior Problem Treatment Program (SBPT) between 2008 and
2014 were chosen from archival data. Data was collected from the subjects' initial intake assessment into the program, as well as their discharge from the program. The assessments were conducted in a classroom setting, or office, after the treatment facilities management team received the state court mandate to assess the juveniles for risk, and sex offender treatment and service needs. Prior to administration, the provider conducted a verbal description of the assessment process and its use to the subject. Following the description, subjects were afforded an opportunity to consent or dissent prior to completing the instruments. All subjects were provided directions and monitoring during the test administration process. Following the administration, the provider collected the data, which was securely stored, and will only be accessible by the researcher for scoring at a later date [48].

\section{Statistical Analysis}

This study utilizes five separate analyses and these data analyses were conducted by way of SPSS. There were five analyses identified for this study. They are as follows: Analysis 1. A 2 × 2 ANOVA was conducted to evaluate the effects of site (Site A versus Site B) and position (juvenile versus staff) on WAS Personal Problem Orientation subscale scores.

Analysis 2. A $2 \times 2$ ANOVA was conducted to evaluate the effects of site (Site A versus Site B) and position (juvenile versus staff) on WAS Support subscale scores.

Analysis 3. A set of $2 \times 2$ ANOVAs were conducted to evaluate the effects of site (Site A versus Site B) and position (juvenile versus staff) on WAS Involvement and WAS Anger and Aggression subscale scores.

Analysis 4. A 2 × 2 ANOVA was conducted to evaluate the effects of site (Site A versus Site B) and position (juvenile versus staff) on WAS System Maintenance domain scores. Analysis 5. A $2 \times 2$ ANOVA was conducted to evaluate the effects of site (Site A versus Site B) and position (juvenile versus staff) on WAS Relationships domain scores.

\section{Results}

Overall, data from the WAS demonstrated statistically significant differences between the social climate perceptions of staff and juveniles concerning the System Maintenance domain scores. Conversely, the data showed a statistically non-significant difference for the Personal Problem Orientation, Support, Involvement, and Anger and Aggression subscales, as well as the higher order Relationship domain scores. Furthermore, statistical differences were discovered during preliminary analysis between the secure care sites (Site A and Site B). 


\section{Mental Health \& Human Resilience International Journal}

Hypothesis 1: Hypothesis 1 stated (Table 2): There will be a statistically significant difference between the WAS Personal Problem Orientation subscale scores of juveniles, and the WAS Personal Problem Orientation subscale scores of the staff in secure care sites. A $2 \times 2$ ANOVA was conducted to evaluate the effects of site (Site $A$ versus Site B) and position (juvenile versus staff) on WAS Personal Problem Orientation subscale scores. The results for the ANOVA indicated a significant main effect for site, $F(1,51)=8.90, p=.004$, partial $\eta 2=.15$, a nonsignificant main effect for position, $F(1,51)=.83, p=.37$, partial $\eta 2=.02$, and a non-significant interaction between site and position, $F(1,51)=3.18, p=.08$, partial $\eta 2=$ .06.The non-significant effect for position demonstrated similar perceptions between juveniles and staff on the WAS Personal Problem Orientation subscale. While the site main effect indicated that BCY scored higher on this subscale score than SCY.

\begin{tabular}{|c|c|c|c|c|c|c|}
\hline Source & $\begin{array}{c}\text { Type III Sum of } \\
\text { Squares }\end{array}$ & df & $\begin{array}{c}\text { Mean } \\
\text { Square }\end{array}$ & F & Sig. & $\begin{array}{c}\text { Partial } \\
\eta^{2}\end{array}$ \\
\hline site2 & 738.819 & 1 & 738.819 & 8.895 & .004 & .149 \\
\hline Name2 & 68.900 & 1 & 68.900 & .830 & .367 & .016 \\
\hline $\begin{array}{c}\text { Site2 } \\
\text { Name2 }\end{array}$ & 264.294 & 1 & 264.294 & 3.182 & .80 & .059 \\
\hline
\end{tabular}

Table 2: Univariate Analysis of Variance for Personal Problem Orientation (without outlier) for Hypothesis 1.

Hypothesis 2: Hypothesis 2 stated (Table 2): There will be a statistically significant difference between the WAS Support subscale scores of juveniles, and the WAS Support subscale scores of the staff in secure care sites. A $2 \times 2$ ANOVA was conducted to evaluate the effects of site (Site A versus Site B) and position (juvenile versus staff) on WAS Support subscale scores. The results for the ANOVA indicated a significant main effect for site, $F(1,52)$ $=6.43, p=.01$, partial $\eta 2=.11$, a non-significant main effect for position, $F(1,52)=1.00, p=.32$, partial $\eta 2=.02$, and a non-significant interaction between site and position, $F(1,52)=1.03, p=.31$, partial $\eta 2=.02$. The nonsignificant effect for position demonstrated similar perceptions between juveniles and staff on the WAS Support subscale. While the site main effect indicated that BCY scored higher on this subscalescore than SCY.

\begin{tabular}{|c|c|c|c|c|c|c|}
\hline Source & $\begin{array}{c}\text { Type III Sum of } \\
\text { Squares }\end{array}$ & df & $\begin{array}{c}\text { Mean } \\
\text { Square }\end{array}$ & F & Sig. & $\begin{array}{c}\text { Partia } \\
\eta^{2}\end{array}$ \\
\hline site2 & 378.594 & 1 & 378.594 & 6.426 & .014 & .110 \\
\hline Name2 & 58.617 & 1 & 58.617 & .995 & .323 & .019 \\
\hline $\begin{array}{c}\text { Site2 } \\
\text { Name2 }\end{array}$ & 60.838 & 1 & 60.838 & 1.033 & .314 & .019 \\
\hline
\end{tabular}

Table 3: Univariate Analysis of Variance for Support for Hypothesis 2.

Hypothesis 3: Hypothesis 3 stated (Tables 4 \& 5): There will be a statistically significant correlation between the WAS Involvement, and Anger and Aggression subscale scores of juveniles, and the WAS Involvement, and Anger and Aggression subscale scores of the staff in secure care sites. A set of $2 \times 2$ ANOVAs were conducted to evaluate the effects of site (Site A versus Site B) and position (juvenile versus staff) on WAS Involvement and WAS Anger and Aggression subscale scores. The results for the first ANOVA indicated a significant main effect for site, $F(1,51)=11.61, p=.001$, partial $\eta 2=.19$, a non-significant main effect for position, $F(1,51)=.21, p=.65$, partial $\eta 2=$ .004 , and a non-significant interaction between site and position, $F(1,51)=.55, p=.46$, partial $\eta 2=.01$. The nonsignificant effect for position demonstrated similar perceptions between juveniles and staff on the WAS Involvement subscale. While the site main effect indicated that $\mathrm{BCY}$ scored higher on this WAS Involvement domain scores than SCY.

\begin{tabular}{|c|c|c|c|c|c|c|}
\hline Source & $\begin{array}{c}\text { Type III Sum of } \\
\text { Squares }\end{array}$ & df & $\begin{array}{c}\text { Mean } \\
\text { Square }\end{array}$ & F & Sig. & $\begin{array}{c}\text { Partial } \\
\eta^{2}\end{array}$ \\
\hline site2 & 718.536 & 1 & 718.536 & 11.611 & .001 & .185 \\
\hline Name2 & 13.272 & 1 & 13.272 & .214 & .645 & .004 \\
\hline $\begin{array}{c}\text { Site2 } \\
\text { Name2 }\end{array}$ & 34.194 & 1 & 34.194 & .553 & .461 & .011 \\
\hline
\end{tabular}

Table 4: Univariate Analysis of Variance for Involvement (without outlier) for Hypothesis 3

The results for the second ANOVA indicated a nonsignificant main effect for site, $F(1,51)=.15, p=.70$, partial $\eta 2=.003$, a non-significant main effect for position, $F(1,51)=1.58, p=.21$, partial $\eta 2=.03$, and a non-significant interaction between site and position, $F(1,51)=1.56, p=.22$, partial $\eta 2=.03$. Thus, there did not appear to be significant differences in WAS Anger and Aggression subscale scores based on site or position.

\begin{tabular}{|c|c|c|c|c|c|c|}
\hline Source & $\begin{array}{c}\text { Type III Sum of } \\
\text { Squares }\end{array}$ & df & $\begin{array}{c}\text { Mean } \\
\text { Square }\end{array}$ & F & Sig. & $\begin{array}{c}\text { Partial } \\
\eta^{2}\end{array}$ \\
\hline site2 & 9.259 & 1 & 9.259 & .146 & .704 & .003 \\
\hline Name2 & 100.635 & 1 & 100.635 & 1.584 & 214 & .030 \\
\hline $\begin{array}{c}\text { Site2 } \\
\text { Name2 }\end{array}$ & 99.344 & 1 & 99.344 & 1.584 .217 & .030 \\
\hline
\end{tabular}

Table 5: Univariate Analysis of Variance for Anger and Aggression (without outlier) for Hypothesis 3.

Hypothesis 4: Hypothesis 4 stated (Table 6): There will be a statistically significant difference between the WAS 


\section{Mental Health \& Human Resilience International Journal}

System Maintenance domain scores of juveniles, and the WAS System Maintenance domain scores of the staff in secure care sites. A $2 \times 2$ ANOVA was conducted to evaluate the effects of site (Site A versus Site B) and position (juvenile versus staff) on WAS System Maintenance domain scores. The results for the ANOVA indicated a significant main effect for site, $F(1,51)=8.50$, $p=.005$, partial $\eta 2=.14$, a significant main effect for position, $F(1,51)=10.25, p=.002$, partial $\eta 2=.17$, and a non-significant interaction between site and position, $F(1,51)=2.39, p=.13$, partial $\eta 2=.05$. The significant effect for position demonstrated differing perceptions between juveniles and staff on the WAS System Maintenance domain. While the site main effect indicated that BCY scored higher on the domain scores than SCY and that staff scored higher than juveniles.

\begin{tabular}{|c|c|c|c|c|c|c|}
\hline Source & $\begin{array}{c}\text { Type III Sum of } \\
\text { Squares }\end{array}$ & df & $\begin{array}{c}\text { Mean } \\
\text { Square }\end{array}$ & F & Sig. & $\begin{array}{c}\text { Partial } \\
\eta^{2}\end{array}$ \\
\hline site2 & 2563.696 & 1 & 2563.696 & 8.501 & .005 & .143 \\
\hline Name2 & 3090.572 & 1 & 3090.572 & 10.248 & .002 & .167 \\
\hline $\begin{array}{c}\text { Site2 } \\
\text { Name2 }\end{array}$ & 721.807 & 1 & 721.807 & 2.393 & .128 & .045 \\
\hline
\end{tabular}

Table 6: Univariate Analysis of Variance for System Maintenance (without outlier) for Hypothesis 4,

Hypothesis 5: Hypothesis 5 stated (Table 7): There will be a statistically significant difference between the WAS Relationship domain scores of juveniles, and the WAS Relationship domain scores of the staff in secure care sites. A 2 × 2 ANOVA was conducted to evaluate the effects of site (Site A versus Site B) and position (juvenile versus staff) on WAS Relationships domain scores. The results for the ANOVA indicated a significant main effect for site, $F(1,51)=18.45, p<.001$, partial $\eta 2=.27$, a non-significant main effect for position, $F(1,51)=3.86, p=.06$, partial $\eta 2$ $=.07$, and a non-significant interaction between site and position, $F(1,51)=2.04, p=.16$, partial $\eta 2=.04$.. The nonsignificant effect for position demonstrated similar perceptions between juveniles and staff on the WAS Relationship domain. While the site main effect indicated that BCY scored higher on this domain score than SCY.

\begin{tabular}{|c|c|c|c|c|c|c|}
\hline Source & $\begin{array}{c}\text { Type III Sum of } \\
\text { Squares }\end{array}$ & df & $\begin{array}{c}\text { Mean } \\
\text { Square }\end{array}$ & F & Sig. & $\begin{array}{c}\text { Partial } \\
\eta^{2}\end{array}$ \\
\hline site2 & 6402.216 & 1 & 6402.21618 .450 & .000 & .266 \\
\hline Name2 & 1340.597 & 1 & 1340.597 & 3.863 & .055 & .070 \\
\hline $\begin{array}{c}\text { Site2 } \\
\text { Name2 }\end{array}$ & 708.910 & 1 & 708.910 & 2.043 & .159 & .039 \\
\hline
\end{tabular}

Table 7: Univariate Analysis of Variance for Relationship (without outlier) for Hypothesis 5.

\section{Discussion}

This study provides promising findings concerning the varied social climate perceptions between juvenile males with sexual behavior problems residing in secure care facilities and the staff who work with them. Analysis of the data demonstrated statistically significant differences in Hypothesis 4, while Hypotheses 1,2,3, and 5 showed statistically non-significant differences. Moreover, statistical differences were discovered during preliminary analysis between the two secure care sites.

The overall findings of this study slightly differ from certain literature that indicates the social climate perceptions of staff and patients are often dissimilar $[24,32,47-49]$. Research has commonly found that staff tends to view the social climate as more positive than the patients do [23,32]. However, the data from this study discovered Hypotheses 1,2,3, and 5 to be statistically nonsignificant regarding the perceptions of staff and juveniles for the Personal Problem Orientation, Support, Involvement, and Anger and Aggression subscales, as well as the higher order Relationship domain scores within the secure care facilities. This is likely due to the importance placed on relational and support variables by the facilities within the OJJ [38]. Staff are trained to prioritize the relationship with the juveniles; thus, the WAS scores concerning relational variables between the staff and juveniles are similar. Furthermore, structure, emphasis on therapeutic interventions, and respectful, supportive relationships that add to the overall feelings of safety. Group climate literature corroborates the claim that an open climate can aid in overall treatment motivation, as well as feelings of safety [50-52].

On the other hand, Hypothesis 4 involved the comparison of perceptions for the System Maintenance domain and did affirm previous literature, which states that perceptions of social climate vary between staff and patients, with staff often scoring higher than the patients $[23,32]$. Furthermore, prior research discovered the most noticeable difference in perceptions for staff and patients were in the aforementioned domain [47]. This difference is attributed to the three subscales (Order and Organization, Program Clarity, Staff Control), which are a part of the System Maintenance domain, that are entirely contingent on the work of the staff. The Order and Organization subscale measures how important order and organization are in the program Jörgensen, Römma, \& Rundmo, 2009) [23]. Also, the Program Clarity subscale measures the extent to which patients know what to 


\section{Mental Health \& Human Resilience International Journal}

expect in their day-to-day routine, and the explicitness of facility rules and procedures Jörgensen, Römma, \&Rundmo, 2009) [23]. The Staff Control subscale measures the extent to which the staff use measures to keep patients under necessary control Jörgensen, Römma, \& Rundmo, 2009) [23].

Thus, the juveniles score lower because there is no responsibility ascribed to them in this domain, and they function strictly as participants. They do not control the organizational structure of the program; rather, they must follow the way in which the OJJ has designed the program. Additionally, there is likely a communication gap between the staff and juveniles, in which the staff believes they are clearly communicating the rules and expectations for the juveniles, while the juveniles do not have a clear sense of their expected roles and rules. Furthermore, the control exerted in a secure care facility is only one-way and the locus of control resides with the staff. Thus, the benefit of skewing positively drastically diminishes for the juvenile. Whereas, the staff would be more apt to perceive their role more positively in light of the responsibility they hold in relation to the maintenance of the facility.

Additionally, while this study did not originally intend to highlight the differences between sites, the statistical difference found in the preliminary analysis made it a point of discussion. Specifically, Hypotheses 1, 2, 4, and 5 all had differences, whereas the Anger and Aggression subscale in Hypothesis 3 did not have a statistically significant difference. The different results between the sites show the importance of assessing individual treatment milieus in order to accurately measure how the staff and juveniles perceive the social climate of the facility. Although this study did not research the specific programs within the respective sites, the following sections will articulate implications and potential future research to understand why the site score were statistically different.

In summary, this study found no statistically significant difference in the social climate perceptions of staff and juveniles regarding the Personal Problem Orientation, Support, Involvement, and Anger and Aggression subscales, as well as the higher order Relationship domain scores. Yet, a statistically significant difference was discovered with the System Maintenance domain scores. The findings of this study are different than what previous research has established, and the following sections will explore how this study can add to the knowledge base of social climate perceptions in juveniles with sexual behavior problems in secure care facilities.
Moreover, there was a statistical difference in site scores on the subscales of Personal Problem Orientation, Support, Involvement, and the higher order domains of Relationship and System Maintenance.

\section{Implications}

Social climate is a variable of secure care facilities that has been recognized as an important piece of the secure care experience [22-25]. However, literature on social climate in secure care for juveniles with sexual behavior problems has been minimal [38]. Therefore, this study offers empirical research concerning the gaps in knowledge reinforcing the importance the social climate perceptions of staff and juveniles with sexual behavior problems in secure care treatment programs.

This study aligns with previous research in assessing and comparing staff perceptions of social climate are compared with juvenile perceptions in an effort to gain a consistent representation of their relationship [32,47,53]. However, several of the findings slightly differ from other literature that indicates the social climate perceptions of staff and patients are often dissimilar [24,32,47-50]. Only one hypothesis (Hypothesis 4) in this study affirmed dissimilarity in perception. This implies that there could be more agreement between staff and juveniles than previously discovered, and an assumption on a divergence in social climate perceptions may not be entirely appropriate.

Furthermore, a significant difference was found in the perceptions of social climate between the two secure care treatment sites, with only the Anger and Aggression subscale of the Ward Atmosphere Scale (WAS) failing to exhibit a significant difference. The implication is that differences remain in the methods secure care facilities use to develop and manage their social climate, even within similar treatment milieus (e.g., secure care treatment for juveniles with sexual behavior problems). Although secure care facilities have similarities and common modes of operation, the results from this study demonstrate that this does not presuppose that the execution is similar.

This study has practical implications for research and application on the perceptions of social climate in secure care treatment facilities. Prior research has contributed to the understanding of social climate and the positive correlation between juvenile satisfaction and motivation for treatment with the juvenile's perception of the social climate $[22,23,50]$. Therefore, it has become increasingly 


\section{Mental Health \& Human Resilience International Journal}

acknowledged within literature that social climate must be highly considered when working in a secure care setting. These facilities can no longer focus solely on the implementation of a set program; rather, staff and administration must value the different factors within social climate in order to provide overall effective treatment.

Additionally, this study added substantial data in the area of differences between two secure care sites that accommodate juveniles with sexual behavior problems. Before this study, Underwood, et al. (2015) [28] conducted a program evaluation for a statewide juveniles with sexual behavior problems program that encompassed eight different treatment sites and used the WAS as one of their outcome measures. However, it was not the main assessment tool used, and the focus was not entirely on the social climate of the sites. Because this study discovered significant differences in social climate perceptions between the two sites, secure care treatment providers have access to more information to aid in the identification of social climate components, as well as improved awareness towards the aspects of social climate that may be affected by dynamic variables (e.g., location, individual staff members).

Also, in an effort to create an effective treatment facility for juveniles with sexual behavior problems, the administration and staff must possess an overarching awareness of how each is experiencing the social climate. Literature does suggest that staff tends to view the social climate as more positive than do the patients [23,32]. The staff should know what variables contribute towards the social climate perception so their work can be intentionally focused on nurturing and maintaining this type of environment. For example, the higher order System Maintenance domain of the Ward Atmosphere Scale (WAS) was statistically significantly different between the staff and juveniles of the two sites, with staff scoring higher. This finding implies staff should be more cognizant of the way in which the treatment facility is ordered and organized. Since staffs are in charge of order and organization, they are also the ones in charge of the importance placed on it. Moreover, the onus is on the staff to clearly and openly articulate routines, rules, and procedures for the juveniles within the secure care facility. Staff may see a clear program direction; however, clients may not this on a day-to-day basis [32]. An overall feeling of safety is developed through structure, emphasis on therapeutic interventions, and respectful, supportive relationships. Group climate literature corroborates the claim that an open climate can aid in overall treatment motivation, as well as feelings of safety $[27,50]$. Finally, this study's results indicate a discrepancy between the perceptions of staff and juveniles concerning the extent to which staff uses measures to keep patients under necessary control. The concept of "necessary control" is highly subjective, and how staff views it may be drastically different from juveniles. Thus, it is vital that staff receive proper training and good, on-site supervision for the adult leaders in an effort to increase their ability to manage the juveniles in the facility. Secure care facilities need to emphasize the creation of high-structure environments in order to decrease the amount of time a juvenile is allowed to engage in unstructured and unsupervised activities [6].

\section{Limitations of the Study}

A limitation in this study is the size of the sample population, with the scores of 56 participants being analyzed. While the sample size assumption was maintained per overall sites, it was violated once the groups were broken into cells based on position (staff or juveniles). It should be noted that in literature with juveniles with sexual behavior problems, a smaller sample size is not abnormal. Although this research yielded different results in a comparison of perception in social climate between staff and juveniles, which has the potential to add a different layer to the literature, any steps towards generalizing the results must be done extremely tentatively. An added limitation is connected to the methodology in which the sample was acquired as archival data and was not randomly selected.

Another limitation of this study is found in the WAS and how it was administered. For one, as was previously discussed, this assessment was not expressly developed for juveniles, nor was it validated in this population. It is conceivable that some items within this tool may be difficult for juveniles to fully comprehend their meaning, or gaps may exist when assessing juveniles as opposed to adults. Moreover, there was only a one-time dispensation of the WAS, and no pre or post-test was given. Only gathering data from one WAS administration truncates the ability to determine if the perception of social climate changes over time. Also, it is unknown at what juncture of the juvenile's stay in the secure care facility the WAS was given. These limitations challenge the ability to fully grasp the context and peripheral variables that may have had an impact on the respondents' perception of social climate in secure care. With this in mind, a related limitation is that the WAS was the only assessment administered, with social climate being the sole variable considered. 


\section{Mental Health \& Human Resilience International Journal}

\section{Recommendations}

There are methodological recommendations that can be made based on the limitations and gaps experienced in this study. Future studies must prioritize increasing the number of juveniles with sexual behavior problems that participate in the studies. This study's sample size $(n=56)$ creates an issue as researchers look to extrapolate the results into broader contexts (e.g., juveniles with sexual behavior problems, secure care treatment facilities, social climate perceptions). A potential solution would be for subsequent studies to include other secure care sites that work with juveniles with sexual behavior problems. By incorporating additional sites, the sample size is improved and the social climates of more milieus can be assessed. Furthermore, the inclusion of more diverse secure care sites (i.e., outside the current study's OJJ region) would allow researchers to study how social climate is developed and perceived in order to gain a more robust understanding of its implications.

The findings of this study, specifically the statistically significant difference between staff and juveniles in their perception of the System Maintenance domain, could be a foundational step for a future study to explore and expound upon the individual subscales of this domain (Order and Organization, Program Clarity, Staff Control). A future study might be a phenomenological qualitative study where the researcher uses the items from the domain to gather a descriptive picture of the lived experience of staff and juveniles in secure care facilities. Because System Maintenance was the only domain or subscale that had a significant difference in positions, it could be valuable to gather a more in-depth representation of staff and juveniles' perceptions and experiences of the System Maintenance. Also, an independent or dependent t-test could be conducted for each subscale based on the responses of the staff and juveniles. A dependent t-test would necessitate a pre and post-testing administration of the System Maintenance domain for each position. Then, an independent t-test analysis could be run to compare the scores of staff and juveniles.

Consequently, another recommendation is that future researchers administer a pre and post-test for staff and juveniles, or intermittently throughout treatment, in order to gauge the presence of treatment progress in regards to social climate perceptions. The addition of at least one more round of WAS assessments opens up a myriad of possibilities for further studies. One such study might be a correlation analysis of the pre and post WAS scores, with the amount of time the juvenile has spent in the secure care facility. Another study that would benefit from pre and post-test WAS assessments could be a quasiexperimental design in which one facility acted as a control group and would not intentionally manage the different social climate variables. The remaining sites would actively develop the various aspects of social climate, per the WAS subscales, and the data would be analyzed to determine if intentionality within the facility impacts the perception of social climate.

Based on the juveniles with sexual behavior problems literature, there are several factors found within this population that potentially affect their perceptions of social climate. One study could be designed as a correlation study between juveniles' depression scores, as assessed by the Children's Depression Inventory-2, and the WAS. In a study conducted by Becker, Kaplan, Tenke, and Tartaglini (1991), they discovered $42 \%$ of the participant offenders confirmed significant depressive symptoms, and had significantly higher self-report of depression than a random sample of juveniles. Similarly, a study might include analysis of the level of anxiety (Children's Manifest Anxiety Scale-2) felt by juveniles in secure care, and how it is correlated with social climate. Maladaptive affect regulation, of which anxiety is a heavy contributor, has been shown to be a precursor towards outward manifestations of behaviors in juveniles with sexual behavior problems [53]. Another study where adding another variable based on juveniles with sexual behavior problems literature, could be a stepwise multiple regression with depression, anxiety, and trauma history (Trauma Symptom Checklist) serving as the independent variables, and social climate as the dependent variable. This type of study could help determine which independent variable has the largest, or smallest, impact on the dependent variable. Literature has been consistent in connecting a history of trauma and neglect with higher rates of depression and anxiety in juveniles with sexual behavior problems [17,55-59].

Broadly speaking, this study addresses a gap in the developing literature regarding a juvenile with sexual behavior problems' time in a secure care facility, and the role social climate plays in their experience. Research has revealed that juvenile satisfaction and motivation for treatment are positively correlated with the juvenile's perception of the social climate $[22,23,50]$. Therefore, it is incumbent upon the administration and staff in secure care facilities to prioritize education on social climate, and be diligent about implementing programs and procedures in an effort to nurture this concept. In their study on 


\section{Mental Health \& Human Resilience International Journal}

interventions for deviant peer influences, Dodge, et al. (2006) [6] identified two factors that can lessen the severity of such effects. The research showed that proper training and good, on-site supervision for the adult leaders were additive factors in their ability to manage the juveniles in such a way that the iatrogenic effect was reduced. The recommendation is that the administration and staff would be trained concerning the subscales and higher order domains of the WAS to incorporate an empirically validated tool to aid in the improvement of social climate. It is a variable that needs to be emphasized within secure care treatment facilities so that staff feels empowered to take an active role in its development.

Furthermore, it is recommended that proper training on social climate would be conducted in order to strengthen the staff's ability to provide effective supervision of the juveniles in the facility. Training is a necessity for those in positions of authority to be on the same page surrounding the importance of the facility's social climate, and they ways in which their supervisory roles will protect it. Supervisors educated in social climate must also be educated in the detrimental impact that unsupervised groups of high-risk juveniles have on it. Deviant peer clusters often engage in behaviors that are reinforced by peer pressure and modeling [8]. Thus, the supervisors can implement the information into the construction of highly structured environments, which decrease the amount of time juveniles are allowed to engage in unstructured and unsupervised activities [6].

\section{Conclusion}

This study was able to compare the differences between the perceived social climate of staff and juveniles with sexual behavior problems residing in secure care. Through the course of preliminary data analysis, a statistically significant difference was discovered between the two sites participating in this research study. Overall, this study increased the knowledge base of social climate as an important variable in secure care facilities, the variance of perceptions in social climate between staff and juveniles, the specific components of social climate, as well as differential perceptions between secure care sites.

The data obtained from this study identified the higher order domain of System Maintenance to be statistically significantly different between staff and juveniles. The analysis reveals a discrepancy in the way these two positions perceive the importance of order and organization in the treatment facility, the clarity of the day-to-day routines of the juveniles as well as the explicitness of rules and procedures, and how the staff use measures to keep patients under necessary control [23]. Additionally, the results of the study noted significant differences in social climate perception between two sites; thus, presenting data that shows a quantifiable difference in treatment perceptions, as well as an opportunity to understand what contributes to these differences. As a result, this study increases the burgeoning foundation of knowledge for a multitude of research areas: juveniles with sexual behavior problems, secure care, staff attitudes, assessments of social climate, and the influence it has on each of these areas. Moreover, the research conducted for this study provides a picture of social climate as a valuable variable to assess within secure care treatment facilities. Subsequent implications and future recommendations add to the foundation, which can continue to increase and fine-tune a secure care facility's ability to follow best care practices through an educated awareness of their social climate.

\section{References}

1. Walker CE, Mc Cormick D (2004) Current practices in residential treatment for adolescent sex offenders: A survey. Journal of Child Sexual Abuse13(3-4): 245255.

2. Edwards R, Whitteaker MK, Beckett R, Bishopp D, Bates A (2012) Adolescents who have sexually harmed: An evaluation of a specialist treatment programme. Journal of Sexual Aggression18(1): 91111.

3. Karokosta O, Underwood L, Merino C, Williams C, Todd S, et al. (2016) Reducing Cognitive Distortions in a Sample of Juveniles with Sexual Behavior Problems. World Journal of Behavioral Science 2: 111.

4. Worling J (1998) Adolescent sexual offender treatment at the SAFE-T program. In Marshall $\mathrm{W}$, Fernandez Y, Hudson S, \& Ward T (Eds.), Sourcebook of Treatment Programs for Sexual Offenders, New York, pp: 353-365.

5. Dishion TJ, McCord J, Poulin F (1999) When interventions harm: Peer groups and problem behavior. American Psychologist 54(9): 755-764.

6. Dodge KA, Dishion TJ, Lansford JE (2006) Deviant peer influences in intervention and public policy for youth. Society for Research in Child Development 20(1): 462-482. 


\section{Mental Health \& Human Resilience International Journal}

7. Gifford-Smith M, Dodge KA, Dishion TJ, McCord J (2005) Peer influence in children and adolescents: Crossing the bridge from developmental to intervention science. Journal of Abnormal Child Psychology 33(3): 255-265.

8. Van Ryzin MJ, Dishion TJ (2014) Adolescent deviant peer clustering as an amplifying mechanism underlying the progression from early substance use to late adolescent dependence. Journal of Child Psychology and Psychiatry 55(10): 1153-1161.

9. McCamey JD (2010) Reducing recidivism in adolescent sexual offenders by focusing on community reintegration. Residential Treatment for Children \& Youth 27(1): 55-67.

10. Christiansen AK, Vincent JP (2013) Characterization and prediction of sexual and nonsexual recidivism among adjudicated juvenile sex offenders. Behavioral Sciences and the Law 31(4): 506-529.

11. Whittle N, Bailey S, Kurtz Z (2006) The needs and effective treatment of young people who sexually abuse: Current evidence. London: Department of Health and National Institute for Mental Health in England.

12. Pratt R (2013) A community treatment model for adolescents who sexually harm: Diverting youth from criminal justice to therapeutic responses. International Journal of Behavioral Consultation and Therapy 8(3-4): 37-42.

13. Abrams LS (2006) Listening to juvenile offenders: Can residential treatment prevent recidivism? Child and Adolescent Social Work Journal 23(1): 61-85.

14. Ebesutani C, Ale C, Luevve A, Viana A, Young J (2011) A practical guide for implementing evidence-based assessment in a psychiatric residential treatment facility: Translating theory into practice. Residential Treatment for Children \& Youth 28(3): 211-231.

15. Hair HJ (2005) Outcomes for children and adolescents after residential treatment: A review of research from 1993-2003. Journal of Child and Family Studies 14(4): 551-575.

16. Ward A (2004) Towards a theory of the everyday: The ordinary and the special in daily living in residential care. Child \& Youth Care Forum 33(3): 209-225.
17. Righthand S, Welch C (2004) Characteristics of youth who sexually offend. Journal of Child Sexual Abuse 13(3-4): 15-32.

18. Henggeler SW, Sheidow AJ (2012) Empirically supported family-based treatments for conduct disorder and delinquency in adolescents. Journal of Marital \& Family Therapy 38(1): 30-58.

19. Ryan JP, Testa MF (2005) Child maltreatment and juvenile delinquency: Investigating the role of placement and placement instability. Children and Youth Services Review 27(3): 227-249.

20. Underwood L, Robinson SB, Mosholder E, Warren KM (2008) Sex offender care for adolescents in secure care: Critical factors and counseling strategies. Clinical Psychology Review 28(6): 917-932.

21. Underwood LA, Warren KM, Talbott L, Jackson L, Dailey FLL (2014) Mental health treatment in juvenile justice secure care facilities: Practice and policy recommendations. Journal of Forensic Psychology Practice 14(1): 55-85.

22. Beazley P, Gudjonsson G (2011) Motivating inpatients to engage with treatment: The role of depression and ward atmosphere. Nordic Journal of Psychiatry 65(2): 95-100.

23. Jörgensen $K$, Römma $V$, Rundmo $T$ (2009) Associations between ward atmosphere, patient satisfaction and outcome. Journal of Psychiatric \& Mental Health Nursing 16(2): 113-120.

24. Schjødt T, Middelboe T, Mortensen EL, Gjerris A (2003) Ward atmosphere in acute psychiatric inpatient care: Differences and similarities between patient and staff perceptions. Nordic Journal of Psychiatry 57(3): 215-220.

25. Nicholls D, Kidd K, Threader J, Hungerford C (2015) The value of purpose built mental health facilities: Use of the Ward Atmosphere Scale to gauge the link between milieu and physical environment. International Journal of Mental Health Nursing 24(4): 286-294.

26. Beech A, Hamilton-Giachritsis C (2005) Relationship between therapeutic climate and treatment outcome in group-based sexual offender treatment programs. Sexual Abuse-A Journal of Research and Treatment 17(2): 127-140. 


\section{Mental Health \& Human Resilience International Journal}

27. Van der Helm P, Stams G, Van Genabeek M, Van der Laan P (2012) Group climate, personality, and selfreported aggression in incarcerated male youth. Journal of Forensic Psychiatry \& Psychology 23(1): 23-39.

28. Van der Helm P, Stams GJ, Van der Laan P (2011) Measuring group climate in prison. The Prison Journal91(2): 158-176.

29. AL-Sagarat A, Moxham L, Curtis J, Crooke P (2014) The perceptions of the ward atmosphere in four Jordanian psychiatric hospitals from the perspective of patients' relatives. Perspectives in Psychiatric Care50(4): 287-293.

30. Smith J, Gross C, Roberts J (1996) The evolution of a therapeutic environment for patients with long-term mental illness as measured by the Ward Atmosphere Scale. Journal of Mental Health5(4): 349-360.

31. Sørlie T, Parniakov A, Rezvy G, Ponomarev O (2010) Psychometric evaluation of the Ward Atmosphere Scale in a Russian psychiatric hospital. Nordic Journal of Psychiatry 64(6): 377-383.

32. Bootsmiller BJ, Davidson WS, Luke DA, Mowbray CT, Ribisl KM, et al. (1997) Social climate differences in a large psychiatric hospital: Staff and client observations. Journal of Community Psychology25(4): 325-336.

33. Marshall WL, Marshall LE, Kingston DA (2011) Are the cognitive distortions of child molesters in need of treatment?. Journal of Sexual Aggression 17(2): 118129.

34. Crump Y, Underwood LA, Dailey FL (2013) Louisiana Office of Juvenile Justice's Comprehensive Statewide Approach to Treating Juvenile Sex Offenders. Corrections Today 60-84.

35. Fagan J(1991) Community-based treatment for mentally disordered juvenile offenders. Journal of Clinical Child Psychology20(1): 42-50.

36. Slattery P, Cherry J, Swift A, Tallon M, Doyle I (2012) From custody to community: Development of assessment and treatment for juveniles serving sentences for sex offences in an Irish context. Journal of Sexual Aggression18(1): 81-90.
37. Hancock PA (2013) In search of vigilance: The problem of iatrogenically created psychological phenomena. American Psychologist 68(2): 97-109.

38. Underwood LA, Dailey FLL, Merino C, Crump Y (2015) Results from a multi-modal program evaluation for a four year statewide juvenile sex offender treatment and reentry program. Journal of Prison Education and Reentry 2(2): 23-36.

39. McCusker K, Gunaydin S (2015) Research using qualitative, quantitative or mixed methods and choice based on the research. Perfusion 30(7): 537-542.

40. Miller VD, Poole MS, Seibold DR, Myers KK, Park HS, et al. (2011) Advancing Research in Organizational Communication Through Quantitative Methodology. Management Communication Quarterly 25(1): 4-58.

41. Lutz W, Hill CE (2009) Quantitative and qualitative methods for psychotherapy research: Introduction to special section. Psychotherapy Research19(4-5): 369373.

42. Fitzgerald SM, RumrillJr PD, Schenker JD (2004) Correlational designs in rehabilitation research. Journal of Vocational Rehabilitation 20(2): 143-150.

43. Moos R (1996) Ward Atmosphere Scale (WAS). Menlo Park, CA: Author.

44. Moos RH, Houts PS (1968) Assessment of the social atmospheres of psychiatric wards. Journal of Abnormal Psychology 73(6): 595-604.

45. Friis S (1986) Characteristics of a good ward atmosphere. Acta Psychiatr Scand 74(5): 469-473.

46. Ellsworth R, Maroney R (1972) Characteristics of psychiatric programs and their effects on patients' adjustment. Journal of Consulting and Clinical Psychology 39(3): 436-447.

47. Brunt D, Rask M (2005) Patient and staff perceptions of the ward atmosphere in a Swedish maximumsecurity forensic psychiatric hospital. The Journal of Forensic Psychiatry \& Psychology 16(2): 263-276.

48. Dailey FLL, Underwood LA, Crump Y, Williams C, Newmeyer M, et al. (2016) Treatment Effectiveness of the Louisiana sexual behavior problem treatment program. International Journal of Psychology and Psychoanalysis 2(2): 1-8. 
49. Day A, Casey S, Vess J, Huisy G (2012) Assessing the therapeutic climate of prisons. Criminal Justice and Behavior 39(2): 156-168.

50. Røssberg JI, Melle I, Oppjordsmoen S, Friss S (2006) Patient satisfaction and treatment environment: A 20year follow-up study from an acute psychiatric ward. Nordic Journal of Psychiatry 60(2): 176-180.

51. Heynen E, Van der Helm G, Stams G, Korebrits A (2014) Measuring group climate in a German youth prison: A German validation of the Prison Group Climate Instrument. Journal of Forensic Psychology Practice 14(1): 45-54.

52. Van der Helm GHP, Stams GJJM (2012) Conflict and coping by clients and group workers in secure residential facilities. In K Oei \& M Groenhuizen (Eds.), Progression in forensic psychiatry: About boundaries, Netherlands, pp: 553-564.

53. Moos R, Shelton R, Petty C (1973) Perceived ward climate and treatment outcome. Journal of Abnormal Psychology 82(3): 291-298.

54. Fanniff AM, Kimonis ER (2014) Juveniles who have committed sexual offenses: A special group? Behavioral Sciences and the Law 32(2): 240-257.
55. Apsche J, Evile MM, Murphy C (2004) The thought change system an empirically based cognitive behavioral therapy for male juvenile sex offenders a pilot study. The Behavior Analyst Today 5(1): 101107.

56. Gerardin P, Thibaut F (2004) Epidemiology and treatment of juvenile sexual offending. Pediatric Drugs6(2): 79-91.

57. Seto MC, Lalumière ML (2010) What is so special about male adolescent sexual offending? A review and test of explanations through meta-analysis. Psychological Bulletin136(4): 526-575.

58. Stevens P, Hutchin K, French L, Craissati J (2013) Developmental and offence-related characteristics of different types of adolescent sex offender: A community sample. Journal of Sexual Aggression19(2): 138-157.

59. Walters JB, Hughes TL, Sutton LR, Marshall SN, Crothers LM, et al. (2013) Maltreatment and depression in adolescent sexual offenders with an Autism Spectrum Disorder. Journal of Child Sexual Abuse 22(1): 72-89.

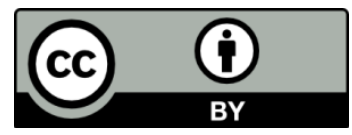

Underwood LA, et al. Comparing Social Climate Perceptions of Staff and Juveniles with Sexual Behavior Problems. Ment Health Hum Resilience Int J 